\title{
A novel test for assessment of anterolateral rotatory instability of the knee: the tibial internal rotation test (TIR test)
}

\author{
Malou E. Slichter ${ }^{1}$, Nienke Wolterbeek ${ }^{1}$, K. Gie Auw Yang ${ }^{1}$, Jacco A. C. Zijl ${ }^{1}$ and Tom M. Piscaer ${ }^{1,2^{*}}$ (D)
}

\begin{abstract}
Background: Rotational instability of the knee may persist after anterior cruciate ligament (ACL) reconstruction, which may be due to insufficiency of anterolateral stabilizing structures. However, no reliable diagnostic tool or physical examination test is available for identifying patients with anterolateral rotatory instability (ALRI). As shown in cadaveric studies, static internal rotation of the knee is increased in higher flexion angles of the knee after severing the anterolateral structures. This might also be the case in patients with an ACL-deficient knee and concomitant damage to the anterolateral structures. The objective of this study is to assess anterolateral rotatory instability of the knee during physical examination with a tibial internal rotation test.

Methods: ACL-injured knees of 52 patients were examined by two examiners and side-to-side differences were compared. Both lower legs were internally rotated by applying manual internal rotation torque to both feet in prone position with the knees in $30^{\circ}, 60^{\circ}$ and $90^{\circ}$ of flexion. For quantification of the amount of rotation in degrees, a torque adapter on a booth was used. Intra-rater, inter-rater and rater-device agreement were determined by calculating kappa $(\mathrm{k})$ for the tibial internal rotation test.
\end{abstract}

Results: Tibial internal rotation is increased in $19.2 \%$ of the patients with $A C L$ injury according to the tibial internal rotation test. Good intra-rater agreement was found for the tibial internal rotation test, $\mathrm{K}_{\mathrm{C}}=0.63(95 \% \mathrm{Cl}-0.02-1.28)$, $p=0.015$. Fair inter-rater agreement was found, $\mathrm{K}_{\mathrm{F}}=0.29(95 \% \mathrm{Cl} 0.02-0.57), p=0.038$. Good rater-device agreement was found, $K_{C}=0.62(95 \% \mathrm{Cl} 0.15-1.10), p=0.001$.

Conclusion: The tibial internal rotation test shows increased tibial internal rotation in a small amount of patients with $A C L$ injury. Even though no gold standard for assessment of increased tibial internal rotation of the knee is available yet, the test can be of additional value. It can be used for assessment of internal rotatory laxity of the knee as part of ALRI in addition to the pivot shift test. No clinical implications should yet be based on this test alone.

Keywords: Anterolateral rotatory instability, Rotatory laxity, Tibial internal rotation, Anterior cruciate ligament, Anterolateral ligament, Physical examination, Pivot shift, Knee, Ligament, Knee instability

\section{Background}

Significant anterolateral rotational instability (ALRI) may persist after anterior cruciate ligament (ACL) reconstruction with a positive pivot shift test in up to $25 \%$ of the patients (Sonnery-Cottet et al., 2015). This might cause functional disability and patient dissatisfaction, and is associated with a reduced rate of return to sport,

\footnotetext{
* Correspondence: t.piscaer@erasmusmc.nl

'Department of Orthopaedic Surgery, St. Antonius hospital, P.O. Box 2500, 3430 EM Nieuwegein, The Netherlands

${ }^{2}$ Department of Orthopaedic Surgery, Erasmus Medical Center, P.O. Box 2040, 3000 CA Rotterdam, the Netherlands
}

and an increase in re-injury (Ayeni et al., 2012; Jonsson et al., 2004; Kaplan et al., 1990; Kocher et al., 2004; Leitze et al., 2005). It is even hypothesized to possibly aggravate the development of osteoarthritis, however, no positive correlation has been found yet (Conteduca et al., 1991; Jonsson et al., 2004; Leitze et al., 2005).

Persevering ALRI may be a result of injury to the anterolateral structures of the knee. Therefore, an additional lateral extra-articular tenodesis (LET) or a reconstruction of the anterolateral ligament (ALL) is proposed by multiple authors to overcome the problem of rotational 
instability (Hewison et al., 2015; Slette et al., 2016; Sonnery-Cottet et al., 2017; Sonnery-Cottet et al., 2015). However, no reliable diagnostic tool is available for identifying patients with ALRI of the knee, while such a tool is essential in order to perform a reliable diagnosis and evaluation of the possible effectiveness of such treatments.

At this moment, the main clinical tests to diagnose ALRI are the pivot shift test (Galway \& MacIntosh, 1980) and anterior drawer test with the foot in $30^{\circ}$ of internal rotation (Larson, 1983; Slocum \& Larson, 1968). Other tests, such as Slocum's test (Slocum et al., 1976), Losee test (Losee et al., 1978) and jerk test (Hughston et al., 1976a) are comparable to the pivot shift test. These tests mainly demonstrate anterior subluxation of the lateral tibia plateau on the lateral femoral condyle. The pivot shift test is an accurate diagnostic test for rupture of the ACL with a sensitivity ranging from $0 \%$ to $93 \%$ and specificity ranging from $82 \%$ to $100 \%$ (Benjaminse et al., 2006; Leblanc et al., 2015). Even though the pivot shift test assesses rotatory laxity of the knee additional to anteroposterior laxity, no distinction can be made between the amount of anteroposterior or rotatory laxity. To which extent the pivot shift contributes in specifically diagnosing ALRI as a consequence of injury to secondary constraints is unclear (Bonanzinga et al., 2017).

Although there is no reliable clinical test for assessment of ALRI of the knee, multiple ex vivo studies have shown that passive internal rotation of the knee is increased at flexion angles greater than $30^{\circ}$ if anterolateral structures, in particular the ALL, are severed in the ACL-deficient knee (Bonanzinga et al., 2017; Dodds et al., 2014; Kittl et al., 2015; Monaco et al., 2012; Parsons et al., 2015; Sonnery-Cottet et al., 2016; Wroble et al., 1993). Passive internal rotation tests of the knee have only been performed in subjects while trying to validate new tools for assessing rotation of the knee (Colombet et al., 2012; Mouton et al., 2012). However, these are mostly expensive tools, time consuming and not easily applicable.

Therefore, we think that ALRI of the knee might also be demonstrated during physical examination with a tibial internal rotation test (TIR test). The purpose of this study is to determine the practicability and rater agreement reliability of a tibial internal rotation test for assessment of internal rotatory instability as part of ALRI in patients with a distorsion of the knee, suspected for ACL injury, in whom rotatory instability should be assessed.

\section{Methods}

Between May and November 2016 a monocenter study was performed for evaluating rater agreement reliability of the TIR test. Inclusion criteria were patients between 18 and 50 years of age with a history of distorsion of the knee and thus strong suspicion on ACL injury or patients with proven ACL injury on magnetic resonance imaging (MRI). Patients with a history of previous injury of the knee or lower limb, a locked knee, complaints of the contralateral knee, rheumatoid disease or other inflammatory disease of the joints, congenital lower limb malformation that could influence rotation of the leg or foot, asymmetrical rotation of the hips and asymmetrical leg axes were excluded. All subjects provided written informed consent and the study was approved by the institutional review board of the author's institution.

\section{Procedure}

Two examiners independently performed physical examination of both knees of each patient to assess internal rotation of the lower legs. The first examiner was one of three experienced orthopaedic surgeons participating in the study. The other examiner was a well-trained medical student blinded for the affected knee. Prior to assessment of the knee, each patient was assessed for symmetric hip rotation and long leg axis.

\section{Physical examination of the knee}

Physical examination of the knee consisted of the tibial internal rotation test as described below. Furthermore, the dial test in prone position (Veltri \& Warren, 1994), the pivot shift test performed according to Galway and MacIntosh (Galway \& MacIntosh, 1980), anterior drawer test with foot in $30^{\circ}$ internal rotation, neutral position and $15^{\circ}$ external rotation (Larson, 1983; Slocum \& Larson, 1968) and Lachmann test (Rossi et al., 2011) were performed. The knees were also assessed for effusion, range of motion, collateral instability (Hughston et al., 1976a) and meniscal injury (Rossi et al., 2011). All tests were scored according to the International Knee Document Committee (IKDC) criteria (Hefti et al., 1993). To objectify true rotation of the knees, internal and external rotation tests were also performed using a quantitative measuring device. All tests were performed in consecutive order to prevent unblinding of the blinded examiner. Physical examination of patients was repeated during a second appointment for assessing the intra-rater agreement. The examiner was blinded for the outcomes of the previous physical examination.

\section{Tibial internal rotation test (TIR test) of the knee}

The TIR test of the knee was performed in prone position. This position allows easy adaptations of the knee flexion angle, good control of the hip extension angle (Mouton et al., 2012) and requires only one examiner. The internal rotation of the lower leg was tested in $30^{\circ}, 60^{\circ}$ and $90^{\circ}$ of flexion of the knees (Fig. 1). The flexion angles were based on data from biomechanical studies (Bonanzinga et al., 2017; Dodds et al., 2014; Kittl et al., 2015; Monaco et al., 2012; Parsons et al., 2015; Sonnery-Cottet et al., 2016; Wroble et al., 1993; Zantop et al., 2007). Both knees were positioned directly next to each other and the hips were 


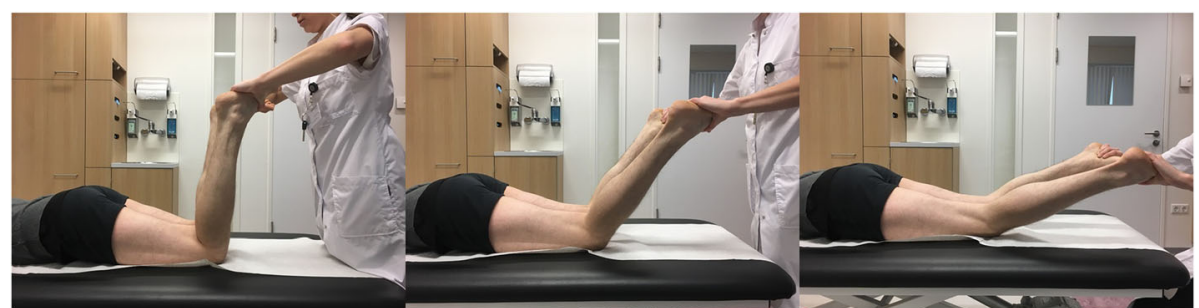

Fig. 1 Performing the TIR test in $90^{\circ}, 60^{\circ}$ and $30^{\circ}$ of flexion of the knees

slightly internally rotated. Internal rotation torque was manually applied on both feet by the examiner, holding the heel. Care was taken to have the ankle in a neutral position. The thigh-foot angle was determined with the feet functioning as pointers of tibial internal rotation relative to the femur (Fig. 2) (Loomer, 1991). Slight internal rotation of the hip was necessary to prevent the feet from touching each other whilst internally rotating the tibia. Based on the dial test (Veltri \& Warren, 1994) and biomechanical studies (Sonnery-Cottet et al., 2016; Tsai et al., 2008; Wroble et al., 1993), $\mathrm{a} \geq 10^{\circ}$ side-to-side difference in thigh-foot angle was considered a positive TIR test (Fig. 2). An additional video file shows this in more detail (see Additional file 1). The test was either scored positive or negative. Attempting to control manual torque equally on both sides the patients were asked whether torque was applied equally on the left and right knee.

\section{Quantification of knee rotation}

For quantification of the amount of internal rotation a device was developed (Fig. 3) (Colombet et al., 2012; Mouton et al., 2012). The patient was placed in prone position with the knees in $30^{\circ}, 60^{\circ}$ and $90^{\circ}$ of flexion. Support was provided for the legs while keeping accurate flexion angles of the knees and a fixed amount of internal rotation of the hips necessary for internal rotation of the tibia such that relative muscle relaxation was possible. Air inflatable walkers (protect.Air ROM Walker, size medium, Medi, Bayreuth, Germany) were used to fixate the ankle relative

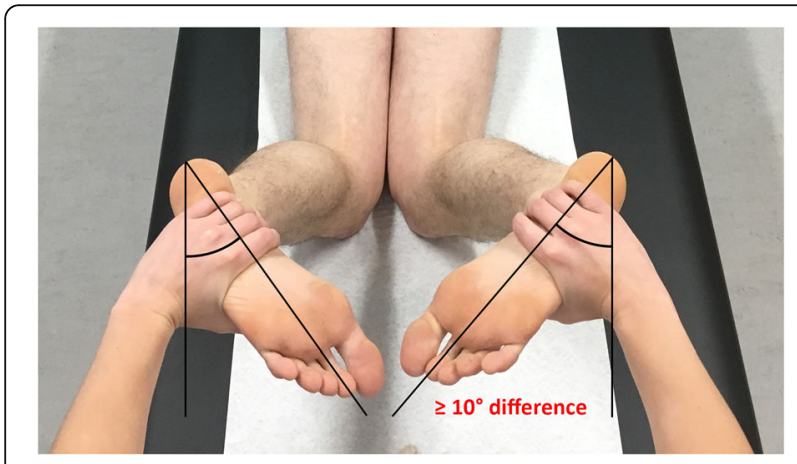

Fig. 2 Positive TIR test of the right knee in $60^{\circ}$ of flexion of the knees to the tibia to minimize the rotation of the ankle. It offers a snug fit without being uncomfortable. A strap was used on both legs just proximal to the knees to avoid natural abduction of the hips. Based on biomechanical studies in vivo, a $6 \mathrm{Nm}$ external rotation and internal rotation torque was applied on both feet by means of a wrench with an electronic torque adapter (Kraftwerk Europe, art. 4081-14, $\pm 2 \%$ ) (Alam \& Bull, 2013; Branch et al., 2010; Markolf et al., 1984; Mouton et al., 2012; Shultz et al., 2007; Tsai et al., 2008). With help of fixed angle gauges the thigh-foot angle was measured during internal and external rotation of the ACL-insufficient knee and contralateral knee with both feet starting in neutral position and not the patient's own resting position of the feet. A side-to-side difference of $\geq 10^{\circ}$ after applying $6 \mathrm{Nm}$ of internal torque was considered a positive TIR test on the device. Also full range of rotation was calculated.

\section{MRI of the ALL and anterolateral structures}

The ALL was retrospectively identified on MRI. The ALL was scored as visualized or non-visualized. If the ALL was visible, it was scored intact or severed including the location of the lesion (proximal or distal of the lateral meniscus). Also, the anterolateral capsule, lateral collateral ligament (LCL), ALL and iliotibial band (ITB) were assessed for surrounding edema, indicating possible

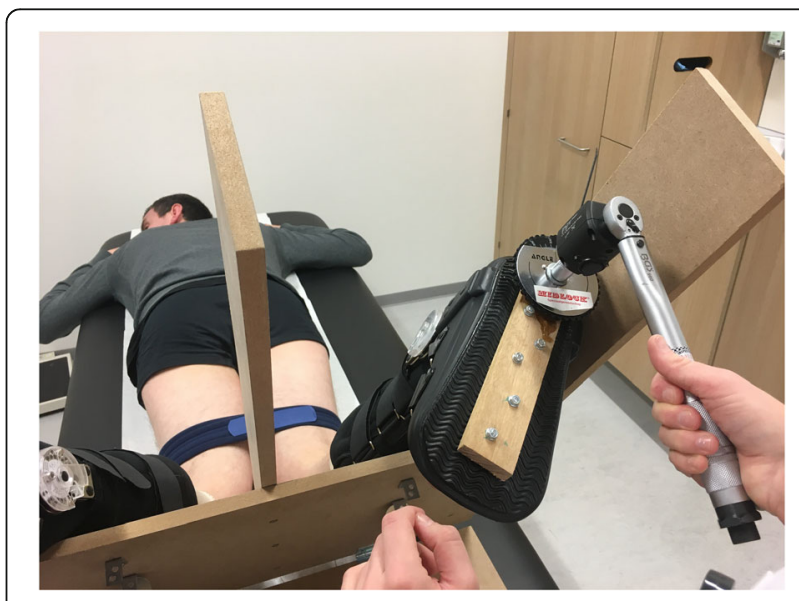

Fig. 3 Internal rotation with $6 \mathrm{Nm}$ torque 
injury to the anterolateral structures of the knee. In addition, the MRI was also assessed for other injury of the knee by a musculoskeletal radiologist as part of routine protocol in patients with ACL injury.

\section{Statistical analysis}

Statistical analysis was performed using Statistical Package of the Social Sciences (SPSS, Chicago, IL, Version 24.0). Because of absence of a gold standard to assess for accuracy of the TIR test, we focused on the degree of agreement between different raters. Primary outcomes are intra-rater agreement, inter-rater agreement and rater-device agreement of the TIR test, secondary outcomes are correlations between the pivot shift test, the anterior drawer test with foot in internal rotation and the TIR test. To determine consistency among raters Cohen's kappa coefficients $\left(\kappa_{C}\right)$ were calculated for intra-rater agreement and rater-device agreement (Cohen, 1960). For assessing intra-rater agreement of the pivot shift test a weighted kappa coefficient $\left(\kappa_{\mathrm{w}}\right)$ was calculated (Cohen, 1968). For determining inter-rater agreement the two raters are considered not unique. Rater number one was considered one of three participating orthopaedic surgeons, therefore Fleiss' kappa coefficients $\left(\kappa_{\mathrm{F}}\right)$ were calculated (Fleiss, 1971). For comparing results of the pivot shift test versus the tibial internal rotation test a rank biserial correlation coefficient was calculated. For comparing a grade II-III pivot shift and positive anterior drawer test with foot in internal rotation to the TIR test the Fisher's exact test was used.

The kappa values are typically interpreted as follows: $<0.00$, poor agreement; $0.00-0.20$, slight agreement; $0.21-0.40$, fair agreement; $0.41-0.60$, moderate agreement; $0.61-0.80$, substantial agreement; and $0.81-1.00$, almost perfect agreement (Landis \& Koch, 1977).

The prevalence of a positive TIR test in patients with ACL injury is unknown. Therefore, no sample size was calculated. Our aim was to include a minimum of $50 \mathrm{sub}$ jects (Donner, 1998). Literature on sample size estimation techniques is limited for rater agreement (Donner, 1998; Donner \& Eliasziw, 1992; Rotondi \& Donner, 2012).

\section{Results}

In this study, 57 patients were included, however, after physical examination 4 patients turned out to meet one of

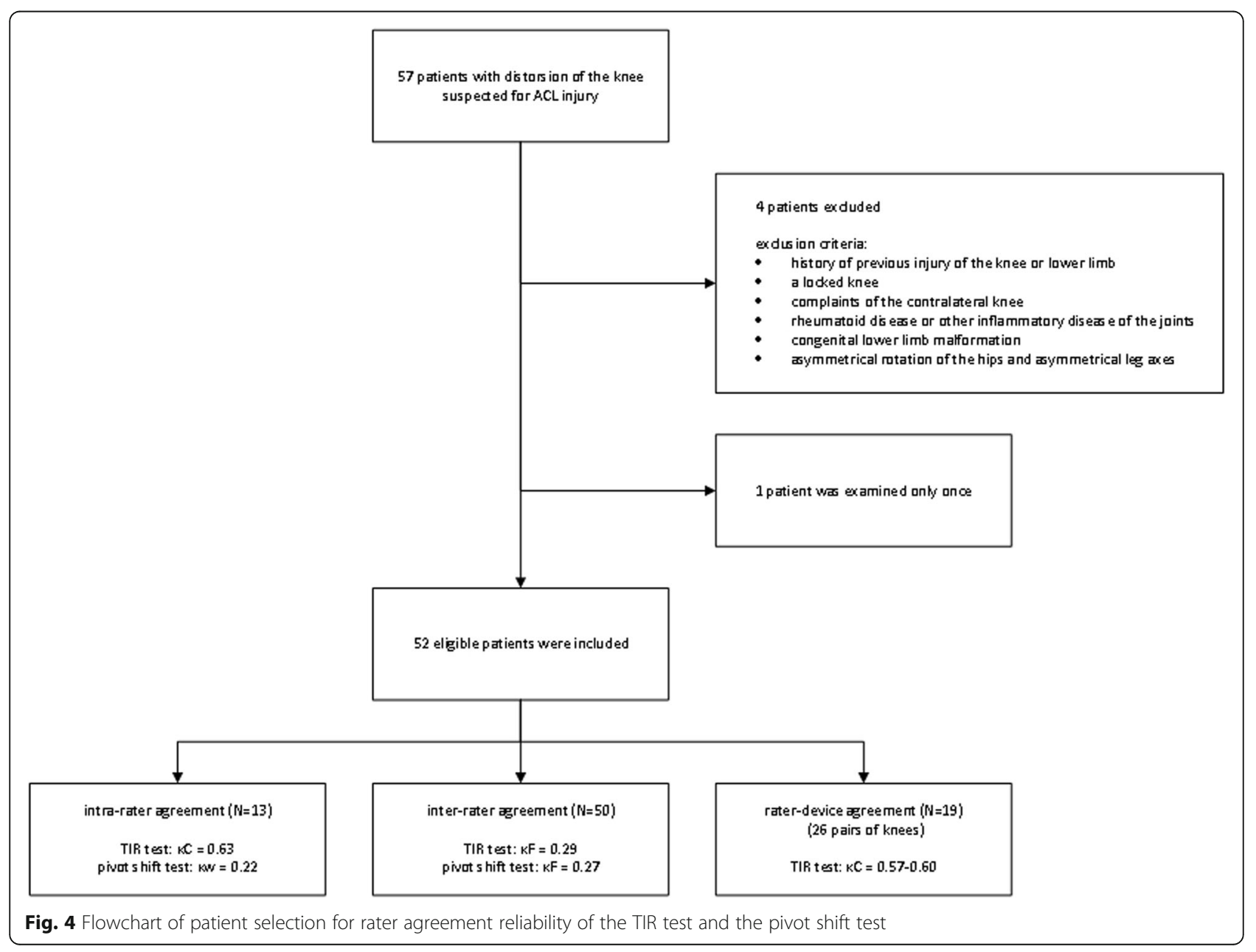


the exclusion criteria and were therefore excluded from the study. Another patient was examined only once by the researcher and was also excluded. Fifty (96\%) patients were assessed for inter-rater agreement and 13 (25\%) patients for intra-rater agreement. For rater-device agreement 19 (37\%) patients were assessed of whom 7 were assessed again during second physical examination, therefore 26 pairs of knees were used (Fig. 4). In 7 (13\%) patients the examiner was not blinded, because the patient accidentally gave out the affected side or was using crutches or an orthosis. For patients characteristics see Table 1.

All included patients showed increased anterior translation as assessed by the Lachmann test, anterior drawer test or pivot shift test when performed by either the orthopaedic surgeon or blinded examiner. No increased posterior translation was found as assessed by the posterior drawer test.

Mean internal rotation, external rotation and total rotation are presented in Table 2 . The maximum mean internal rotation was $32.2^{\circ}$ in $30^{\circ}$ of knee flexion. No statistically significant rotational differences were found between injured and healthy knee.

The TIR test was easily applicable by the examiner and the patient did not experience any discomfort during the test.

In total the blinded examiner found a positive TIR test on the injured knee in $10(19.2 \%)$ patients and found a positive test on the healthy knee in $7(13.5 \%)$ patients

Table 1 Patient characteristics of 52 patients

\begin{tabular}{|c|c|}
\hline gender (men/women) & $31(59.6 \%) / 21(40.4 \%)$ \\
\hline mean age in years $\pm S D$ & $29.9 \pm 9.2$ \\
\hline mean body mass index in $\mathrm{kg} / \mathrm{m}^{2} \pm \mathrm{SD}$ & $24.4 \pm 2.9$ \\
\hline $\begin{array}{l}\text { mean time between trauma and physical } \\
\text { examination in weeks } \pm S D\end{array}$ & $23.4 \pm 31.6$ \\
\hline$\leq 6$ weeks & $12(23.1 \%)$ \\
\hline$>6$ weeks & $39(75 \%)$ \\
\hline no recollection of trauma & $1(1.9 \%)$ \\
\hline $\begin{array}{l}\text { mean time between first physical examination } \\
\text { and second physical examination in weeks } \pm \text { SD }\end{array}$ & $5.6 \pm 3.8$ \\
\hline $\begin{array}{l}\text { mean time between trauma and MRI in } \\
\text { weeks } \pm \text { SD }\end{array}$ & $16.4 \pm 26.1$ \\
\hline injured side (left/right) & $20(38.5 \%) / 32(61.5 \%)$ \\
\hline unblinding of researcher & $7(13.5 \%)$ \\
\hline inability of relative muscle relaxation & $19(36.5 \%)$ \\
\hline $\begin{array}{l}\text { physical therapy prior to first physical } \\
\text { examination }\end{array}$ & $37(71.2 \%)$ \\
\hline \multicolumn{2}{|l|}{ treatment } \\
\hline $\mathrm{ACL}$ reconstruction & $29(55.8 \%)$ \\
\hline additional lateral extraarticular tenodesis ${ }^{a}$ & $4(13.8 \%)$ \\
\hline conservative treatment & $18(34.6 \%)$ \\
\hline diagnostic trajectory & $5(9.6 \%)$ \\
\hline
\end{tabular}

atemaire or modified Lemaire procedure
Table 2 The amount of tibial rotation in degrees in 26 pair of knees suspected for unilateral ACL injury with a $6 \mathrm{Nm}$ torque

\begin{tabular}{llll}
\hline & injured side & intact side & mean difference \\
\hline 30 & & & \\
internal rotation & $32.2 \pm 11.8$ & $32.2 \pm 9.7$ & $0.0 \pm 11.1$ \\
external rotation & $39.4 \pm 9.6$ & $37.3 \pm 9.6$ & $2.1 \pm 8.4$ \\
total rotation & $71.6 \pm 17.3$ & $69.4 \pm 16.5$ & $2.2 \pm 15.0$ \\
$60^{\circ}$ degrees of flexion & & & \\
internal rotation & $24.5 \pm 7.8$ & $25.5 \pm 7.5$ & $-1.1 \pm 8.5$ \\
external rotation & $39.7 \pm 6.7$ & $38.0 \pm 8.9$ & $1.8 \pm 8.5$ \\
total rotation & $64.2 \pm 11.8$ & $63.5 \pm 13.8$ & $0.7 \pm 14.0$ \\
$90^{\circ}$ degrees of flexion & & & \\
internal rotation & $24.1 \pm 8.9$ & $25.3 \pm 9.4$ & $-1.2 \pm 12.3$ \\
external rotation & $40.8 \pm 8.1$ & $39.1 \pm 10.2$ & $1.7 \pm 7.2$ \\
total rotation & $64.9 \pm 11.6$ & $64.4 \pm 15.3$ & $0.5 \pm 13.8$ \\
\hline
\end{tabular}

${ }^{a}$ Not statistically significant

during the first physical examination. The orthopaedic surgeon found a positive TIR test in 5 (9.5\%) patients, all in the injured knee. The overall proportion of agreement between raters was $82 \%$. On the internal rotation device $6(23.1 \%)$ of 26 pair of knees had a positive test on the injured knee. Overall agreement between the blinded examiner and the device was $65 \%$.

Fair inter-rater agreement was found for the TIR test in $30^{\circ}, 60^{\circ}$ and all flexion angles combined, $\mathrm{K}_{\mathrm{F}}=0.29$ (95\% CI: 0.02 to 0.57 ), $p=0.04$ (Table 3).

Substantial intra-rater agreement was found for $30^{\circ}$, $60^{\circ}$, and all flexion angles combined, $\kappa_{C}=0.63$ (95\% CI: -0.02 to 1.28$), p=0.02$. No kappa could be calculated for $90^{\circ}$ of flexion, because no positive TIR test was found during the second examination.

A moderate to substantial rater-device agreement was found for $30^{\circ}, 60^{\circ}, 90^{\circ}$ and all flexion angles combined by calculating Cohen's kappa. Their respective values are $\mathrm{K}_{\mathrm{C}}=0.60$ (95\% CI: -0.19 to 1.01 ), $p=0.002$ for $30^{\circ}$ and $60^{\circ}$ of flexion in the knees. For $90^{\circ}$ of flexion $\mathrm{K}_{\mathrm{C}}=0.62$ (95\% CI: 0.15 to 1.10), $p=0.001$. For all flexion angles combined $\kappa_{C}=0.57$ (95\% CI: 0.20 to 0.94 ), $p=0.003$.

For physical examination tests in relation to a positive and negative TIR test see Table 4. From 11 patients with a positive TIR test in $30^{\circ}, 60^{\circ}$, and $/$ or $90^{\circ}, 2$ (18.2\%) patients had an additional MCL lesion. From 41 patients with a negative TIR test, 17 (41.5\%) patients had additional injury to one of the collateral ligaments.

There is no statistically significant association between a pivot shift grade I-III and grade II-III and a positive TIR test in $30^{\circ}, 60^{\circ}, 90^{\circ}$ of knee flexion and all flexion angles combined as assessed by the Fisher's exact test. Also no statistically significant association was found between a positive TIR test and a positive anterior drawer test with foot in $30^{\circ}$ of internal rotation. A rank biserial correlation 
Table 3 Rater-agreement of the TIR test and the pivot shift test

\begin{tabular}{|c|c|c|c|c|c|}
\hline & $N=$ & K & SE & 95\% confidence interval & $P$ value \\
\hline intra-rater $\left(\mathrm{K}_{\mathrm{C}}\right)$ & 13 & & & & \\
\hline $30^{\circ}$ of flexion & & 0.63 & 0.33 & $-0.02-1.28$ & 0.015 \\
\hline $60^{\circ}$ of flexion & & 0.63 & 0.33 & $-0.02-1.28$ & 0.015 \\
\hline $90^{\circ}$ of flexion ${ }^{a}$ & & - & & & \\
\hline all flexion angles combined & & 0.63 & 0.33 & $-0.02-1.28$ & 0.015 \\
\hline pivot shift test $\left(\mathrm{K}_{\mathrm{w}}\right)$ & & 0.22 & 0.39 & $-0.55-0.99$ & n.s. \\
\hline inter-rater $\left(\mathrm{K}_{\mathrm{F}}\right)$ & 50 & & & & \\
\hline $30^{\circ}$ of flexion & & 0.29 & 0.14 & $0.02-0.57$ & 0.038 \\
\hline $60^{\circ}$ of flexion & & 0.29 & 0.14 & $0.02-0.57$ & 0.038 \\
\hline $90^{\circ}$ of flexion & & -0.08 & 0.14 & $-0.35-0.20$ & n.s. \\
\hline all flexion angles combined & & 0.29 & 0.14 & $0.02-0.57$ & 0.038 \\
\hline pivot shift test & & 0.27 & 0.09 & $0.09-0.44$ & 0.003 \\
\hline rater-device $\left(k_{C}\right)$ & 26 & & & & \\
\hline $30^{\circ}$ of flexion & & 0.60 & 0.21 & $0.19-1.01$ & 0.002 \\
\hline $60^{\circ}$ of flexion & & 0.60 & 0.21 & $0.19-1.01$ & 0.002 \\
\hline $90^{\circ}$ of flexion & & 0.62 & 0.24 & $0.15-1.10$ & 0.001 \\
\hline all flexion angles combined & & 0.57 & 0.19 & $0.20-0.94$ & 0.003 \\
\hline
\end{tabular}

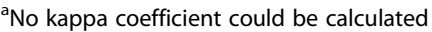

n.s. not significant

did not show a statistically significant correlation between the pivot shift test and the TIR test for all flexion angles of the knee and all flexion angles combined (Table 5).

Based on the pivot shift test grade II and III, 13 (34\%) patients were diagnosed with ALRI by the orthopaedic surgeon compared to 21 (64\%) patients diagnosed by the blinded examiner. The overall proportion of agreement between examiner and orthopaedic surgeon was $48 \%$. The pivot shift test showed similar inter-rater agreement compared to the tibial internal rotation test with $\mathrm{K}_{\mathrm{F}}=$ 0.27 (95\% CI: 0.09 to 0.44 ), $p=0.003$ (Table 3).

Of 50 (96\%) patients the MRI of the ACL-injured knee was retrospectively reviewed, with mean time between trauma and MRI being $16.4 \pm 26.1$ weeks. From two patients the MRI was not assessable. Of all patients, $44(88.0 \%)$ patients had ACL injury on MRI. In 36 (81.8\%) patients the ALL was visualized on MRI. Because of poor imaging, 6 MRIs were not suitable for assessment of the ALL. In 7 (19.4\%) cases the status of the ALL was rated as abnormal of which 4 (57\%) had a distal lesion. In $26(52.0 \%)$ patients slight edema surrounding at least one of the anterolateral structures, such as the anterolateral capsule, LCL, ALL or ITB, was found. For concomitant injury seen on MRI, see Table 6.

\section{Discussion}

This study is the first to investigate manual application of internal torque to the tibia as a physical diagnostic test for ALRI in a representative group with high incidence of ACL rupture. The TIR test is easily applicable and no discomfort is experienced by the patient.

Fair inter-rater agreement, substantial intra-rater agreement and a moderate to substantial rater-device agreement for the TIR test were found. No significant correlations were found between the TIR test and the pivot shift test and anterior drawer test with foot in internal rotation. This strengthens the idea that the TIR test assesses a different aspect of ALRI than the aforementioned tests do. The TIR test only demonstrates increased tibial internal rotatory laxity and can therefore be of additional value to the dynamic pivot shift test.

Some inaccuracies of the TIR test might occur. When manual torque is applied to the foot, rotation and supination occurs in the ankle joint. However, assuming that there are no side-to-side differences in ankle joint motion, this should have no effect on the outcome of a positive or negative TIR test. Also, lower limb malformation that could influence rotation of the leg or foot was an exclusion criterium. In addition, it is possible that the position of the ankle could have influenced the rater-device agreement, since positioning can differ between the manual TIR test and internal rotation performed on the device and patients were more able to relax while perfoming internal rotation on the device. We have chosen a cut-off value of $\geq 10^{\circ}$ side-to-side difference based on the dial test and in our opinion a $\geq 10^{\circ}$ side-to-side difference can be estimated without help of an additional goniometer. This value can be influenced by individual variety of rotation laxity and applied torque of the 
Table 4 Physical examination in 52 patients suspected for ACL injury with a positive and negative TIR test

\begin{tabular}{|c|c|c|}
\hline & $\begin{array}{l}\text { positive TIR test } \mathrm{t}^{\mathrm{a}} \\
(N=11)\end{array}$ & $\begin{array}{l}\text { negative TIR test } \mathrm{t}^{\mathrm{a}} \\
(\mathrm{N}=41)\end{array}$ \\
\hline \multicolumn{3}{|l|}{ pivot shift test ${ }^{\mathrm{a}, \mathrm{b}}$} \\
\hline 0 to $1+$ & - & $4(9.8 \%)$ \\
\hline $1+$ to $2+$ & $6(54.5 \%)$ & $19(46.3 \%)$ \\
\hline $2+$ to $3+$ & $3(27.3 \%)$ & $10(24.4 \%)$ \\
\hline $3+$ & - & $1(2.4 \%)$ \\
\hline no assessment possible & $2(18.2 \%)$ & $7(17.1 \%)$ \\
\hline \multicolumn{3}{|c|}{ anterior drawer test with foot in internal rotation ${ }^{a}$} \\
\hline negative & $4(36.3 \%)$ & $26(63.4 \%)$ \\
\hline positive & $7(63.6 \%)$ & $15(36.6 \%)$ \\
\hline \multicolumn{3}{|l|}{ varus gapping ${ }^{a, c}$} \\
\hline grade $A$ & $11(100.0 \%)$ & $34(82.9 \%)$ \\
\hline grade $B$ & - & $5(12.2 \%)$ \\
\hline grade $C$ & - & $2(4.9 \%)$ \\
\hline grade $D$ & - & - \\
\hline \multicolumn{3}{|l|}{ valgus gapping ${ }^{\mathrm{a}, \mathrm{c}}$} \\
\hline grade $\mathrm{A}$ & $9(81.8 \%)$ & $31(75.6 \%)$ \\
\hline grade $B$ & $2(18.2 \%)$ & $9(22.0 \%)$ \\
\hline grade $C$ & - & $1(2.4 \%)$ \\
\hline grade D & - & - \\
\hline
\end{tabular}

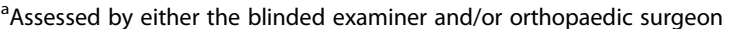
b0 (normal; negative), 1+ (nearly normal; glide), 2+ (abnormal; clunk), 3+ (severely abnormal; gross), according to the 2000 IKDC objective knee examination score

'Grade A (normal; 0-2 mm), grade B (nearly normal; 3-5 mm), grade C (abnormal; 6-10 mm), grade $D$ (severely abnormal; $>10 \mathrm{~mm}$ ), according to the 2000 IKDC objective knee examination score

examiner. We do not know if this results in overestimation or underestimation of positive results of the TIR test.

Other inaccuracies may occur due to the patient's reflex resisting instability tests due to discomfort. Also, secondary stabilizers contributing to the function of the primary stabilizers might decrease the magnitude of the instability demonstrated by the clinical test (Larson,

Table 5 Correlation between the TIR test and other diagnostic tests for ALRI

\begin{tabular}{lllll}
\hline & $\begin{array}{l}\text { pivot shift } \\
\text { test }(N=52)\end{array}$ & $\begin{array}{l}\text { pivot shift test } \\
\text { grade II-III } \\
(N=33)\end{array}$ & $\begin{array}{l}\text { anterior drawer test with } \\
\text { foot in internal rotation } \\
(N=52)\end{array}$ \\
\cline { 2 - 3 } & $\begin{array}{l}r \\
(\mathrm{rb})\end{array}$ & $\begin{array}{l}P \\
\text { value }\end{array}$ & FE (P value $)$ & FE (P value $)$ \\
\hline $30^{\circ}$ of flexion & 0.05 & 0.815 & 1 & 0.264 \\
$60^{\circ}$ of flexion & 0.05 & 0.815 & 1 & 0.264 \\
$90^{\circ}$ of flexion & 0.16 & 0.503 & 1 & 0.379 \\
$\begin{array}{l}\text { all flexion } \\
\text { angles } \\
\text { combined }\end{array}$ & 0.05 & 0.815 & 1 & 0.264 \\
\hline
\end{tabular}

$\mathrm{r}(\mathrm{rb})=$ rank biserial correlation

$\mathrm{FE}=$ Fisher's exact test
Table 6 Features on MRI of the injured knee of 50 patients

\begin{tabular}{|c|c|}
\hline \multicolumn{2}{|l|}{$\mathrm{ACL}$} \\
\hline intact & $4(8 \%)$ \\
\hline contusion & $2(4 \%)$ \\
\hline partial rupture & $9(18 \%)$ \\
\hline rupture & $35(70 \%)$ \\
\hline \multicolumn{2}{|l|}{$\mathrm{PCL}$} \\
\hline intact & $46(92 \%)$ \\
\hline contusion & $1(2 \%)$ \\
\hline buckling & $3(6 \%)$ \\
\hline \multicolumn{2}{|l|}{ LCL } \\
\hline intact & $44(88 \%)$ \\
\hline sprain & $5(10 \%)$ \\
\hline partial rupture & $1(2 \%)$ \\
\hline \multicolumn{2}{|l|}{$\mathrm{MCL}$} \\
\hline intact & $38(76 \%)$ \\
\hline sprain & $7(14 \%)$ \\
\hline partial rupture & $1(2 \%)$ \\
\hline rupture & $4(8 \%)$ \\
\hline lesion of the lateral meniscus & $13(26 \%)$ \\
\hline lesion of the medial meniscus & $20(40 \%)$ \\
\hline \multicolumn{2}{|l|}{ ALL } \\
\hline visualized & $36(72 \%)$ \\
\hline normal & $29(80.6 \%)$ \\
\hline abnormal & $7(19.4 \%)$ \\
\hline non visualized & $8(16 \%)$ \\
\hline no assessment possible & $6(12 \%)$ \\
\hline edema surrounding anterolateral structures ${ }^{\mathrm{a}}$ & 26 (52\%) \\
\hline
\end{tabular}

${ }^{\mathrm{a}}$ Slight edema surrounding at least one of the following structures: anterolateral capsule, LCL, ALL and/or ITB

1983; Noyes et al., 1980). Greater knee laxity is thought to be associated with an increased demand of leg musculature to maintain joint stability (Shultz et al., 2007). Therefore, this effect can probably be even more attributed to patients that have had physical therapy.

In $7(13.5 \%)$ patients examined by the blinded examiner a positive TIR test was found on the contralateral healthy knee. These outcomes were later scored as a negative test for determining inter-rater agreement, because during this study and in a clinical setting the orthopaedic surgeon is never blinded for the affected side. Also some patients notified after examination that they had unwittingly protected their affected knee. Other biasing factors of static and dynamic rotatory laxity are time interval between trauma and the physical examination and the time interval for assessing intra-rater agreement reliability. Both these factors lead to differences in the amount of effusion and pain the patient is experiencing. 
Noyes et al. (Noyes et al., 1991) found that the pivot shift test varied substantially between examiners in cadaveric knees. As far as we know, only one study of Labbe et al. (Labbe et al., 2011) reports a kappa value for the inter-rater agreement of the pivot shift test with $\mathrm{K}=0.83$. Nonetheless, in their study three clinicians evaluated only 12 subjects of whom four subjects had ACL-intact knees and eight subjects had varying degrees of joint instability due to a rupture of the ACL. This limits the inter-rater agreement to only eight subjects with ACL injury. Also the three clinicians were in total agreement of only five of the 12 subjects (42\%) (Labbe et al., 2011). According to our results the pivot shift test has slight inter-rater agreement with a Fleiss' kappa of 0.27 and an overall agreement of $48 \%$. These dissimilarities in outcomes might be the result of the different sample sizes used, different forces applied by the examiner during the maneuver, and grading of the pivot shift test relies on the examiner's perception of the change of motion that occurs. This makes it a highly subjective test and patient guarding may limit the reliability of the test (Lane et al., 2008; Noyes et al., 1991). Remarkably, several patients guarded the pivot shift test performed by the blinded examiner, which might be due to experienced discomfort during the maneuver performed by the orthopaedic surgeon beforehand. The subjectivity of the pivot shift test confirms the need for other diagnostic tests for assessing rotatory laxity such as the TIR test.

Comparing our data of internal, external and total rotation to other studies, similar results were found. Mayr et al. (Mayr et al., 2011) found no significant difference in internal and external rotation between ACL-injured and healthy knee. They report on a side-to-side difference in healthy knees of $5.5^{\circ}$ and $9.0^{\circ}$ of internal and external rotation respectively, while other studies (Alam \& Bull, 2013; Mouton et al., 2012) state that physiologic side-to-side differences in tibial rotation averaged between $1.53^{\circ}$ and $3.5^{\circ}$. Our study found non-significant side-to-side differences ranging from $-1.2^{\circ}$ to $2.2^{\circ}$ between healthy and injured knee. Only Markolf et al. (Markolf et al., 1984) report on a statistical significant difference of $3.0^{\circ}$ between ACL-deficient and healthy knee concerning the total rotation. Comparing the data remains challenging because of highly variable conditions and testing methodologies (Colombet et al., 2012; Mouton et al., 2012).

Many structures are described that contribute to ALRI and increased internal rotation. Cadaveric biomechanical studies show that the contribution of the ACL in restraining tibial internal rotation torque decreases as the flexion angle of the knee increases while the contribution of the ALL increases, especially in flexion angles $\geq 30^{\circ}$ of the knee (Bonanzinga et al., 2017; Monaco et al., 2012; Parsons et al., 2015; Sonnery-Cottet et al., 2016; Wroble et al., 1993). This suggests that increased passive internal rotation as assessed by the TIR test may be the result of injury of the
ALL leading to ALRI. Other structures that also contribute to internal rotatory stability of the knee are the ITB (Kittl et al., 2015; Sonnery-Cottet et al., 2016), the LCL (Parsons et al., 2015; Wroble et al., 1993; Zantop et al., 2007), the medial collateral ligament (MCL), posterolateral structures (Wroble et al., 1993; Zantop et al., 2007) and the menisci (Musahl et al., 2010). The TIR test cannot distinguish between internal rotatory laxity as a result of damage to anterolateral structures or damage to other secondary internal rotatory stabilizers. This has to be taken into account when considering a surgical treatment for adjustment of internal rotatory instability. Therefore, the clinician should interpret the outcome of the TIR test in combination with varusand valgus gapping. Also, attention must be paid to the movement of the lateral and medial tibial plateau when performing the anterolateral drawer test and posteromedial drawer test in order to distinct increased internal rotatory laxity as a consequence of either anterolateral- or posteromedial rotatory instability (PMRI) (Larson, 1983; Slocum \& Larson, 1968). However, PMRI only occurs in the PCL-deficient knee, since if the tibial plateau moves posteriorly during internal rotation the PCL tightens and locks the joint surfaces together (Hughston et al., 1976a).

How to identify patients that will benefit from additional surgical procedures at time of ACL reconstruction, such as an ALL reconstruction or LET is still subject of debate. A clear definition of ALRI with an objective quantification method of injury would be useful, so that indications for reconstruction of the anterolateral capsule can be defined (Colombet et al., 2012; Laprade, 2016). At the moment, the indication for an additional procedure is primarily based on the orthopaedic surgeon's intuition and experience, while bearing in mind the patient characteristics such as age, laxity and level of sport (Sonnery-Cottet et al., 2017). Also multiple orthopaedic surgeons (Monaco et al., 2012; Sonnery-Cottet et al., 2017) believe that anterolateral structures must be repaired during time of ACL reconstruction if a pivot shift grade '2+' or ' $3+$ ' is present, even though multiple structures in the knee other than the ALL can influence the highly subjective pivot shift test (Hughston et al., 1976b; Lane et al., 2008). This subjectivity of the pivot shift test can result in a high variety in the decision of whether or not to perform an additional LET or ALL reconstruction amongst orthopaedic surgeons. Since the pivot shift test is also influenced by other structures than the anterolateral, it may be that not all patients identified with ALRI by the pivot shift test may benefit from a LET or ALL reconstruction. Therefore, the TIR test can be a valuable addition in filling up the gap in diagnosing internal rotatory laxity as part of ALRI.

Several studies show that the ALL can be identified on MRI (Caterine et al., 2014; Claes et al., 2014; Devitt et al., 2017; Van Dyck et al., 2016; Helito et al., 2014; Kosy et al., 
2015; Porrino et al., 2015; Taneja et al., 2015) and ultrasound imaging (Capo et al., 2017; Cavaignac et al., 2016; Klos et al., 2017; Oshima et al., 2016). These studies show suboptimal results with detection rates on MRI ranging from $51 \%$ to $100 \%$ in healthy knees and the ACL-deficient knee, with a pooled analysis of $96 \%$ (Van Der Watt et al., 2015). Nonetheless, their ability to evaluate injury to the ALL is still unclear and no clinical protocols are yet focusing on assessing the ALL in the ACL-deficient knee. This means that orthopaedic surgeons are still mainly dependable on physical examination. In our study we found similar detection rates of the ALL.

Several limitations are present in this study. First of all, there is no gold standard available for diagnosing ALRI, therefore no sensitivity and specificity could be determined for the TIR test. Also, our measurements could not be compared to a true measurement of rotatory instability of the knee. The consequence is that is not clear if real internal rotatory laxity is assessed by the TIR test. Furthermore, during the examination the orthopaedic surgeon was not blinded. No orthopaedic surgeon had a positive tibial internal rotation test on the healthy contralateral knee in comparison to the blinded examiner. Also, the scoring of laxity by the examiners was in a semi-quantitative fashion and the sensation of laxity and accuracy of grading instability is determined by the examiner's experience (Larson, 1983). As for the patients, we experienced that not all patients were able to fully relax during physical examination. These aforementioned points may have resulted in false positive or negative testing and consequently in lower kappa values for rater agreement. Also, we do not know whether the time interval between ACL injury and physical examination influences the amount of internal rotation and thus the outcome of the TIR test. No correlation between the ALL and edema of the anterolateral structures on MRI and the TIR test was determined, since there is a lack of a gold standard for identifying the ALL, and heterogeneity of the time intervals between trauma, physical examination and MRI, which could both result in inaccuracies. Also, in the future we would like to compare the results to a healthy control group for further clarification.

Methods of measuring knee kinematics vary greatly and no gold standard exists in assessing ALRI. Further research is needed to develop methods for diagnosing ALRI. Clear definitions of rotatory laxity should be defined before reliable and standardized methods can be developed to quantify dynamic and static rotatory laxity. The focus on quantification devices of tibial rotation seems promising, which can lead to validation of the TIR test in vivo. Also, the ultimate aim is to identify which patients benefit most from additional reconstruction of the anterolateral aspects of the knee and to eliminate concomitant rotatory laxity using an individualized approach for each patient.

\section{Conclusion}

In certain patients with unilateral ACL injury increased tibial internal rotation was shown by means of the TIR test. The TIR test has comparable agreement to the pivot shift test according to our study and can therefore be helpful in demonstrating internal rotatory laxity in addition to the dynamic pivot shift test. A positive TIR test should alert the clinician on possible concomitant injury, however no clinical implications should be based on this test alone. If using the TIR test, we recommend performing the test in prone position with $30^{\circ}, 60^{\circ}$, and $90^{\circ}$ of flexion in the knees in patients with symmetrical position of both feet relative to the tibia. Further research and validation of this novel test is needed.

\section{Additional file}

Additional file 1: Performing the TIR test in $60^{\circ}$ of flexion of the knees, with a positive test on the right knee. (MOV $11468 \mathrm{~kb}$ )

\section{Abbreviations}

ACL: Anterior cruciate ligament; ALL: Anterolateral ligament;

ALRI: Anterolateral rotatory instability; FE: Fisher's exact; IKDC: International

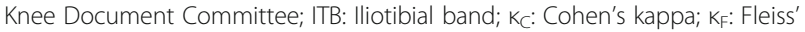
kappa; Kw: weighted kappa; LCL: Lateral collateral ligament; LET: Lateral extraarticular tenodesis; MCL: Medial collateral ligament; MRI: Magnetic resonance imaging; Nm: Newtonmeter; PMRI: Posteromedial rotatory instability; r(rb): rank biserial correlation; SE: Standard error; SPSS: Statistical Package of the Social Sciences; TIR test: Tibial internal rotation test

\section{Acknowledgements}

The authors would like to thank Mark A. Slichter for providing technical help in the development of the knee rotation quantification device.

\section{Availability of data and materials}

The dataset supporting the conclusions of this article is available on request.

\section{Authors' contributions}

MES contributed to the design and coordination of the study, developed the internal rotation device, acquisition of the data by examining all patients and assessment of the MRIs, performed the statistical analysis and interpretation, and drafted and revised the manuscript. NW contributed to the design of the study and coordination, helped with interpreting the data and revising the manuscript. TMP contributed to the design of the study and coordination, helped developing the internal rotation device, and participated in collection and interpretation of the data and revising the manuscript. JACZ contributed to the design of the study, collection of the data and revising the manuscript. KGAY contributed to the design of the study, collection of the data and revising the manuscript. All authors read and approved the final manuscript.

\section{Ethics approval and consent to participate}

This study was approved by the internal research board of the local institution. All subjects provided written informed consent.

\section{Consent for publication}

Not applicable.

\section{Competing interests}

The authors declare that they have no competing interests.

\section{Publisher's Note}

Springer Nature remains neutral with regard to jurisdictional claims in published maps and institutional affiliations. 
Received: 23 February 2018 Accepted: 22 June 2018 Published online: 09 August 2018

\section{References}

Alam M, Bull AMJ, deW TR, Amis AA (2013) A clinical device for measuring internal-external rotational laxity of the knee. Am J Sports Med 41:87-94

Ayeni OR, Chahal M, Tran MN, Sprague S (2012) Pivot shift as an outcome measure for ACL reconstruction: a systematic review. Knee Surg Sports Traumatol Arthrosc 20:767-777

Benjaminse A, Gokeler A, Van Der Schans CP (2006) Clinical diagnosis of an anterior cruciate ligament rupture: a meta-analysis. J Orthop Sports Phys Ther 36:267-288

Bonanzinga T, Signorelli C, Grassi A, Lopomo N, Bragonzoni L, Zaffagnini S, Marcacci M (2017) Kinematics of ACL and anterolateral ligament. Part l: combined lesion. Knee Surg Sports Traumatol Arthrosc 25:1055-1061

Branch TP, Browne JE, Campbell JD, Siebold R, Freedberg HI, Arendt EA, Lavoie F, Neyret P, Jacobs CA (2010) Rotational laxity greater in patients with contralateral anterior cruciate ligament injury than healthy volunteers. Knee Surg Sports Traumatol Arthrosc 18:1379-1384

Capo J, Kaplan DJ, Fralinger DJ, Adler RS, Campbell KA, Jazrawi LM, Alaia MJ (2017) Ultrasonographic visualization and assessment of the anterolateral ligament. Knee Surg Sports Traumatol Arthrosc 25:3134-3139

Caterine S, Litchfield R, Johnson M, Chronik B, Getgood A (2014) A cadaveric study of the anterolateral ligament: re-introducing the lateral capsular ligament. Knee Surg Sports Traumatol Arthrosc 23:3186-3195

Cavaignac E, Wytrykowski K, Reina N, Pailhé R, Murgier J, Faruch M, Chiron P (2016) Ultrasonographic identification of the anterolateral ligament of the knee. Arthroscopy 32:120-126

Claes S, Bartholomeeusen S, Bellemans J (2014) High prevalence of anterolateral ligament abnormalities in magnetic resonance images of anterior cruciate ligament-injured knees. Acta Orthop Belg 80:45-49

Cohen J (1960) A coefficient of agreement for nominal scales. Educ Psychol Meas 20:37-46

Cohen J (1968) Weighted kappa: nominal scale agreement with provision for scaled disagreement or partial credit. Psychol Bull 70:213-220

Colombet P, Jenny JY, Menetrey J, Plaweski S, Zaffagnini S (2012) Current concept in rotational laxity control and evaluation in $\mathrm{ACL}$ reconstruction. Orthop Traumatol Surg Res 98S:S201-S210

Conteduca F, Ferretti A, Mariani PP, Puddu G, Perugia L (1991) Chondromalacia and chronic anterior instabilities of the knee. Am J Sports Med 19:119-123

Devitt BM, O'Sullivan R, Feller JA, Lash N, Porter TJ, Webster KE, Whitehead TS (2017) MRI is not reliable in diagnosing of concomitant anterolateral ligament and anterior cruciate ligament injuries of the knee. Knee Surg Sports Traumatol Arthrosc 25:1345-1351

Dodds AL, Halewood C, Gupte CM, Williams A, Amis AA (2014) The anterolateral ligament: anatomy, length changes and association with the Segond fracture. Bone Joint J 96-B:325-331

Donner A (1998) Sample size requirements for the comparison of two or more coefficients of inter-observer agreement. Stat Med 17:1157-1168

Donner A, Eliasziw M (1992) A goodness-of-fit approach to inference procedures for the kappa statistic: confidence interval construction, significance-testing and sample size estimation. Stat Med 11:1511-1519

Fleiss J (1971) Measuring nominal scale agreement among many raters. Psychol Bull 76:378-382

Galway HR, Maclntosh DL (1980) The lateral pivot shift: a symptom and sign of anterior cruciate ligament insufficiency. Clin Orthop Relat Res 147:45-50

Hefti E, Müller W, Jakob RP, Stäubli HU (1993) Evaluation of knee ligament injuries with the IKDC form. Knee Surg Sports Traumatol Arthrosc 1:226-234

Helito CP, Helito PVP, Costa HP, Bordalo-Rodriques M, Pecora JR, Camanho GL, Demange MK (2014) MRI evaluation of the anterolateral ligament of the knee: assessment in routine 1.5-T scans. Skelet Radiol 43:1421-1427

Hewison CE, Tran MN, Kaniki N, Remtulla A, Bryant D, Getgood AM (2015) Lateral extra-articular tenodesis reduces rotational laxity when combined with anterior cruciate ligament reconstruction: a systematic review of the literature. Arthroscopy 31:2022-2034

Hughston JC, Andrews JR, Cross MJ, Moschi A (1976a) Classification of knee ligament instabilities part I. The medial compartment and cruciate ligaments. J Bone Joint Surg Am 58-a:159-172

Hughston JC, Andrews JR, Cross MJ, Moschi A (1976b) Classification of knee ligament instabilities part II. The lateral compartment. J Bone Joint Surg Am 58-a:173-179
Jonsson H, Riklund-Ahlström K, Lind J (2004) Positive pivot shift after ACL reconstruction predicts later osteoarthrosis: 63 patients followed 5-9 years after surgery. Acta Orthop Scand 75:594-599

Kaplan N, Wickiewicz TL, Warren RF (1990) Primary surgical treatment of anterior cruciate ligament ruptures: a long-term follow-up study. Am J Sports Med 18:354-358

Kittl C, El-Daou H, Athwal KK, Gupte CM, Weiler A, Williams A, Amis AA (2015) The role of the anterolateral structures and the $\mathrm{ACL}$ in controlling laxity of the intact and ACL-deficient knee. Am J Sports Med 44:345-354

Klos B, Scholtes M, Konijnenberg S (2017) High prevalence of all complex Segond avulsion using ultrasound imaging. Knee Surg Sports Traumatol Arthrosc 25: 1331-1338

Kocher MS, Steadman JR, Briggs KK, Sterett WI, Hawkins RJ (2004) Relationships between objective assessment of ligament stability and subjective assessment of symptoms and function after anterior cruciate ligament reconstruction. Am J Sports Med 32:629-634

Kosy JD, Mandalia VI, Anaspure R (2015) Characterization of the anatomy of the anterolateral ligament of the knee using magnetic resonance imaging. Skelet Radiol 44:1647-1653

Labbe DR, De Guise JA, Mezghani N, Godbout V, Grimard G, Baillargeon D, Lavigne P, Fernandes J, Ranger P, Hagemeister N (2011) Objective grading of the pivot shift phenomenon using a support vector machine approach. $J$ Biomech 44:1-5

Landis JR, Koch GG (1977) The measurement of observer agreement for categorical data. Biometrics 33:159-174

Lane CG, Warren R, Pearle AD (2008) The pivot shift. J Am Acad Orthop Surg 16: $679-688$

Laprade RF (2016) Editorial commentary: defining the anatomy of the anterolateral aspect of the knee among experts is clearly needed. Arthroscopy 32:842-843

Larson RL (1983) Physical examination in the diagnosis of rotatory instability. Clin Orthop Relat Res 172:38-44

Leblanc MC, Kowalczuk M, Andruszkiewicz N, Simunovic N, Farrokhyar F, Turnbull TL, Debski RE, Ayeni OR (2015) Diagnostic accuracy of physical examination for anterior knee instability: a systematic review. Knee Surg Sports Traumatol Arthrosc 23:2805-2813

Leitze Z, Losee RE, Jokl P, Johnson TR, Feagin JA (2005) Implications of the pivot shift in the ACL-deficient knee. Clin Orthop Relat Res 436:229-236

Loomer RL (1991) A test for knee posterolateral rotatory instability. Clin Orthop Relat Res 264:235-238

Losee RE, Johnson TR, Southwick O (1978) Anterior subluxation of the lateral tibial plateau. A diagnostic test and operative repair. J Bone Joint Surg Am 60:1015-1030

Markolf KL, Kochan A, Amstutz HC (1984) Measurement of knee stiffness and laxity in patients with documented absence of the anterior cruciate ligament. J Bone Joint Surg Am 66-a:242-253

Mayr HO, Hoell A, Bernstein A, Hube R, Zeiler C, Kalteis T, Suedkamp NP, Stoehr A (2011) Validation of a measurement device for instrumented quantification of anterior translation and rotational assessment of the knee. Arthroscopy 27: 1096-1104

Monaco E, Ferretti A, Labianca L, Maestri B, Speranza A, Kelly MJ, D’Arrigo C (2012) Navigated knee kinematics after cutting of the ACL and its secondary restraint. Knee Surg Sports Traumatol Arthrosc 20:870-877

Mouton C, Theisen D, Pape D, Nührenbörger C, Seil R (2012) Static rotational knee laxity in anterior cruciate ligament injuries. Knee Surg Sports Traumatol Arthrosc 20:652-662

Musahl V, Citak M, O'Loughlin PF, Choi D, Bedi A, Pearle AD (2010) The effect of medial versus lateral meniscectomy on the stability of the anterior cruciate ligament-deficient knee. Am J Sports Med 38:1591-1597

Noyes FR, Grood ES, Butler DL, Malek M (1980) Clinical laxity tests and functional stability of the knee: biomechanical concepts. Clin Orthop Relat Res 146:84-89

Noyes FR, Grood ES, Cummings JS, Wroble RR (1991) An analysis of the pivot shift phenomenon. The knee motions and subluxations induced by different examiners. Am J Sports Med 19:148-155

Oshima T, Nakase J, Numata H, Takata Y, Tsuchiya H (2016) Ultrasonography imaging of the anterolateral ligament using real-time virtual sonography. Knee 23:198-202

Parsons EM, Gee AO, Spiekerman C, Cavanagh PR (2015) The biomechanical function of the anterolateral ligament of the knee. Am J Sports Med 43:669-674

Porrino J, Maloney E, Richardson M, Mulcahy H, Ha A, Chew FS (2015) The anterolateral ligament of the knee: MRI appearance, association with 
the Segond fracture, and historical perspective. AJR Am J Roentgenol 204:367-373

Rossi R, Dettoni F, Bruzzone M, Cottino U, D'Elicio DG, Bonasia DE (2011) Clinical examination of the knee: know your tools for diagnosis of knee injuries. Sport Med Arthrosc Rehabil Ther Technol 3:25

Rotondi MA, Donner A (2012) A confidence interval approach to sample size estimation for interobserver agreement studies with multiple raters and outcomes. J Clin Epidemiol 65:778-784

Shultz SJ, Shimokochi Y, Nguyen AD, Schmitz RJ, Beynnon BD, Perrin DH (2007) Measurement of varus-valgus and internal-external rotational knee laxities in vivo - part l: assessment of measurement reliability and bilateral asymmetry. J Orthop Res 25:981-988

Slette EL, Mikula JD, Schon JM, Marchetti DC, Kheir MM, Turnbull TL, LaPrade RF (2016) Biomechanical results of lateral extra-articular tenodesis procedures of the knee: a systematic review. Arthroscopy 32:2592-2611

Slocum DB, James SL, Larson RL, Singer KM (1976) Clinical test for anterolateral rotary instability of the knee. Clin Orthop Relat Res 118:63-69

Slocum DB, Larson RL (1968) Rotatory instability of the knee. Its pathogenesis and a clinical test to demonstrate its presence. J Bone Joint Surg Am 50-a:211-225

Sonnery-Cottet B, Daggett M, Fayard J-M, Ferretti A, Helito CP, Lind M, Monaco E, De Pádua VBC, Thaunat M, Wilson A, Zaffagnini S, Zijl J, Claes S (2017) Anterolateral ligament expert group consensus paper on the management of internal rotation and instability of the anterior cruciate ligament - deficient knee. J Orthop Traumatol 18:91-106

Sonnery-Cottet B, Lutz C, Daggett M, Dalmay F, Freychet B, Niglis L, Imbert P (2016) The involvement of the anterolateral ligament in rotational control of the knee. Am J Sports Med 44:1209-1214

Sonnery-Cottet B, Thaunat M, Freychet B, Pupim BHB, Murphy CG, Claes S (2015) Outcome of a combined anterior cruciate ligament and anterolateral ligament reconstruction technique with a minimum 2-year follow-up. Am J Sports Med 43:1598-1605

Taneja AK, Miranda FC, Braga CAP, Gill CM, Hartmann LGC, Santos DCB, Rosemberg LA (2015) MRI features of the anterolateral ligament of the knee. Skelet Radiol 44:403-410

Tsai AG, Musahl V, Steckel H, Bell KM, Zantop T, Irrgang JJ, Fu FH (2008) Rotational knee laxity: reliability of a simple measurement device in vivo. BMC Musculoskelet Disord 9:35

Van Der Watt L, Khan M, Rothrauff BB, Ayeni OR, Musahl V, Getgood A, Peterson D (2015) The structure and function of the anterolateral ligament of the knee: a systematic review. Arthroscopy 31:569-582

Van Dyck P, Clockaerts S, Vanhoenacker FM, Lambrecht V, Wouters K, de Smet E, Gielen JL, Parizel PM (2016) Anterolateral ligament abnormalities in patients with acute anterior cruciate ligament rupture are associated with lateral meniscal and osseous injuries. Eur Radiol European Radiology 26:3383-3391

Veltri DM, Warren RF (1994) Posterolateral instability of the knee. J Bone Joint Surg Am 76-a:460-472

Wroble RR, Grood ES, Cummings JS, Henderson JM, Noyes FR (1993) The role of the lateral extraarticular restraints in the anterior cruciate ligament-deficient knee. Am J Sports Med 21:257-263

Zantop T, Schumacher T, Diermann N, Schanz S, Raschke MJ, Petersen W (2007) Anterolateral rotational knee instability: role of posterolateral structures. Arch Orthop Trauma Surg 127:743-752

\section{Submit your manuscript to a SpringerOpen ${ }^{\circ}$ journal and benefit from:}

- Convenient online submission

- Rigorous peer review

- Open access: articles freely available online

- High visibility within the field

- Retaining the copyright to your article

Submit your next manuscript at $>$ springeropen.com 